\title{
Neuro-cognitive rehabilitation among patients with spinal cord injury treated with stem cell
}

\author{
Afsanrh Zarghi ${ }^{1 *}$, Alireza Zali ${ }^{2}$, Farzad Ashrafi ${ }^{3}$ and Sam Moazezi ${ }^{4}$ \\ *Correspondence: dr.a.zarghi@hotmail.com

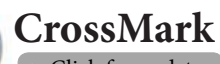 \\ $\leftarrow$ Click for updates \\ 1Professor, Department of Neuroscience, Functional Neurosurgery Research Center of Shahid Beheshti University of Medical \\ Sciences, Tehran, Iran. \\ ${ }^{2}$ Professor, Functional Neurosurgery Research Center of Shahid Beheshti University of Medical Sciences, Tehran, Iran. \\ ${ }^{3}$ Assistant Professor, Functional Neurosurgery Research Center of Shahid Beheshti University of Medical Sciences, Tehran, Iran. \\ ${ }^{4}$ Medical Student, Functional Neurosurgery Research Center of Shahid Beheshti University of Medical Sciences, Tehran, Iran.
}

\begin{abstract}
Discovery of the potential use of stem cells in neural repair and regeneration on patients with Spinal cord injury (SCI) is a noteworthy development in the neurosciences. In this review, several ongoing studies are presented that aim to describe neurobiology of spinal cord injury, role of stem cell therapy in neural repair and importance of neuro-cognitive rehabilitation (NCR) among patients with SCI who treated with stem cell.

Result: NCR is a group of designed techniques that is for the promotion of cognitive domains. It is a science of restoring cognitive processing which affects the molecular and cellular recovery rehabilitation by integrating behavioral and cognitive changes. Neuro-cognitive deficits are potential side effects of stem cell therapy (SCT). The promotion of cognitive neuroscience rehabilitation has made it a priority with the help of interventional procedures. Cognitive impairments after SCT in patients with SCI are considered huge health challenges. Intervention in the passive skills also can lead to NCR that includes designed experience on the basis of nerve and brain function and structure. Neuroplasticity and reorganization of cortical damage by morphological and physiological reactions in nerve reconstruction techniques are the basis of neuro-cognitive rehabilitation which is affected by the environment, stimulation complexity, repeated tasks and motivation.
\end{abstract}

Keywords: Neuro-cognitive, rehabilitation, spinal cord injury, stem cell

\section{Introduction}

SCT should be predictable in the future. Also, it should be performed through the help of many recent advances obtained in the neurobiology laboratory. Now, it is clear that central axonal regeneration is possible under special laboratory conditions for mammals. Inhibitor molecules have been inactivated and a permissive environment is provided [1-6]. As stem cells can differ and turn to central nervous system (CNS), laboratory facilities and possibilities have become more widespread. Treatment for $\mathrm{SCl}$, based on stem cell technology, is one of the available options. Not much time has passed since the Spinal Cord Injuries were considered as a major cause of human death [7]. Although there is a great urgency and necessity for applying the results of recent researches to patients; it is strictly recommended that human trials should not begin until the experimental methodology is completely worked out on an appropriate animal model. The truth is that most physicians do not recognize that loss of sensation may be equal with paralysis or disability among patients with SCI [8]. Rehabilitation outcomes are determined by the changes in cognitive impairments. In this review, several ongoing studies are presented that aim to describe the importance of neuro- cognitive rehabilitation among patients who treated with stem cell. Different phases of SCl treatment can cause impairment in cognitive domains. These issues are used for a very accurate examination in patients who are suspected of $\mathrm{SCl}$.

\section{Review \\ Neurobiology of spinal cord injury}

Aggravation of injury is very common and even when the patient is hospitalized this problem occurs. In the acute phase, transient or permanent damages to axons in terms of histology have been shown, and this is performed by immunochemical activity of 'A Beta' dense proteins (this protein is a component of amyloid precursor protein or APP within axons). The transport system of these axons has interrupted, but rather is able to recover. Those who remain healthy may be remyelinated with peripheral Schwann cell myelin $[\mathbf{9}, \mathbf{1 0}]$. It is known that other bare axons, formatting terminal bulb, have been disrupted $[11,12]$. The first sign of injury is cord edema, which can cause swelling that is due to leakage of fluid from the capillaries. This occurs within minutes after the injury and usually is associated with white matter parenchymal hemorrhage. Central gray matter necrosis is a common result of flexion and extension 
Zarghi et al. Neuroscience Discovery 2014,

injuries. Solid cord injury without any visible hemorrhage or evident parenchymal disruption is unusual. Clinically, this type of injury is associated with central cord syndrome; the main lesions will generate in the white matter of the lateral columns that are adjacent to the central gray matter $[1,3,6,7]$.

\section{Neural changes in SCI Stages}

Occurrence of necrosis in acute phase and in lower-scale apoptosis are causes of neurons and glia death in the vicinity of the injured area. The impact of excitotoxic shock is also evident with the destruction caused by free radicals at the molecular level. Vascular changes that occur in response to this phenomenon are initiated by cytokines released from damaged tissues, which may happen in the first 12 hours and represented by the migration of polymorphonuclear leucocytes and vascular dilation. It seems that after these events, lymphocytes and macrophages soon after injury within 24 hours to 48 hours will present in this area. The number and proportion of these cells largely varies from case to case. Within 72 hours, fat-laden macrophages are greatly found in the area. These cells immerse myelin fragments and turn them into ineffective or neutral fats using enzymes. Thus they easily take them away from this area and eventually will destroy them. It is thought that reactive changes cause secondary damages to spinal cord parenchyma, which may at first seem quite intact [8,13-19]. In this phase, cellular and molecular changes such as edema, hemorrhage, necrosis, apoptosis, excitotoxic shock, cellular migration, myelin fragments and reactive changes cause cognitive changes after $\mathrm{SCl}$. It can justify the role of acute phase to induce cognitive impairment which requires rehabilitation. The next stage, subacute stage, is characterized by forming cavity to remove debris which is performed by continuing the activity of macrophages. Astrocytes that appear for the first time about 5 days after injury reproduce and locate on glial fibers, and finally will form irregular heteromorphic networks. Depending on the extent of arachnoid and dural tearing, collagenous fibrosis may be prominent inside and around the cord lesion, so that the subarachnoid space is removed. The rate of collagenous scar formation is variable and usually proportional to the amount of hemorrhage. Beyond the immediate injury, many changes will occur in the remaining cord tissues. Degeneration of Wallerian axons is a continuous process distal to the neuronal cell body. Over time, axons are decomposed distal to the injured area and their myelin sheaths are broken up into globules. Degeneration of axons and myelin breakdown can be seen near the end of the lesion (in the caudal), in the motor pathways, and in the rostral part of sensory tracts. Macrophages remove debris and Astrocytes lay down fibers parallel to the lost axons and thus may lead to isomorphic gliosis. In addition, the loss of Wallerian also occurs in patients who survived for 12 months or more. Other changes are more suitable including reflex deviations and the 'plastic' neurophysiological effects at the synaptic level arising from changes in the inhibitory signals, thresholds, neurotransmitter release and neuroendocrines. These 'plastic' changes are continuous [20-27]. Neural changes in this phase such as cellular migration and reproduction, irregular heteromorphic networks, collagenous fibrosis, degeneration of Wallerian axons, degeneration of axons and myelin breakdown, isomorphic gliosis and the plastic neurophysiological effects cause neural network changes after $\mathrm{SCl}$. They are important factors in $\mathrm{SCl}$ subacute phase to induce neuro-cognitive changes.

In chronic or end stage of $\mathrm{SCl}$, the lesion is typically composed of a multilocular cavity holes that pass through the vascular-glial pathways and are associated with regenerated nerve roots. Astrocytes and collagen fibers encounter with different degrees of various compounds and surround the cavities. It should be noted that multilocular cystic cavities are not related to posttraumatic syringomyelia but represent the remaining processes of the body healing. Appropriate amounts of gliosis, collagen, new blood vessels and macrophages (some of which are filled with iron), cause regeneration of nerve roots. There is also this possibility that a limited amount of central axons regeneration occurred spontaneously, however; direct demonstration of this fact in humans (after death) is impossible. Central axons that myelinated by the Schwann cells have been found, but it may either be remyelinated (the same so that is described above), or possibly central axons are made to be regenerated by Schwann cells. In this final stage, the lesion is more or less static except when it is supposed that continuous increase in the loss of Wallerian degeneration of spinal tracts occur above or below the lesion and this can effect on the plasticity of neuronal synaptic network [18,28-36]. Neural changes in chronic phase included: inappropriate amounts of gliosis, collagen, new blood vessels, macrophages, cellular migration and reproduction, irregular heteromorphic networks, collagenous fibrosis, remyelinization, regeneration, degeneration of Wallerian axons and effect on the plasticity of neuronal synaptic network. These factors in $\mathrm{SCl}$ chronic phase can cause neuro-cognitive changes after SCT. Other complications that occur in the long term are due to the aging process, such as atheroma of feeding arteries and intervertebral disc degeneration. This change and ligamentum flavum hypertrophy may cause spinal stenosis. These effects may be the reason for neurological changes in the long term $[22,24,37]$. Injured structures in the Spinal cord model include: Long tract, including the corticospinal that may be disordered functionally or anatomically, neurons found in the level of injury, which most of them are motor neurons and vascular disorders increasing remyelination. It has been shown that conventional treatment regimens include immunomodulatory drugs contribute to regenerate long tracts. Today most diets are leading to myelination and are critical for axons regeneration. The reproduction of astrocytes leads to gliosis, which in all probability will inhibit the growth of axons [28-31,35,36,38-42]. Neurons to corticospinal are located in motor cortex and are not the aim for stem cells restoration. 
Cellular and molecular changes in neural system with SCT in SCI

SCT in SCl could potentially stimulate endogenous stem cells to reproduce along the neural pathway. These differentiated cells will migrate around the central canal across the ducts, similar to what is provided by radial glia in cortex. They fill and restore in the anterior horn cells, which have been injured at the damage level. To control switches or messenger, as an example, they strengthen this process and advance neural stem cells along the nerve lines using Shh [43]. However, restoration of anterior horn cells at damage levels will provide only a small amount of clinical benefits. If it is proved that the endogenous cells population is inadequate, stem cells can be used to stimulate nerve cells in vivo. These cells must reach the appropriate area, this can be a location in which nerve cells are lost or can be along the neurons normal migration pathway. The more appropriate target for treatment in spinal cord injury is long tracts. Impairment in these areas is the reason for loss of motor, sensory and autonomic neurons below damage level. Neurons that are involved in this case are at the root input levels in the brain or the sensory pathway. Lush glial reproduction in damage level is detrimental for the regeneration of axons. The goal of mentioned treatments is little reproduction of glial. It has been shown that after cord injury, Oligodendrocyte processes lead to increased myelination in the tracts. It has been shown that mesenchymal stromal cells facilitate axons regeneration in animal models. However, this can occur according to emergence and development of oligodendrocyte processes. Conventional methods of treatment using methylprednisolone or newer tests, including rho inhibitors can also act as a second mode. In cell based treatments, to protect or regenerate tracts, mononuclear cells or lymphocyte ancestors must be used to act as immunomodulators and scavengers. This can be a way for the growth of axons [44-50]. Stem cells in vivo may have a tendency to differentiate along oligodendrocytic lines before reaching injured areas. The discovery of neural stem cells could light glimmer of hope for patients with neurodegenerative diseases or those who have suffered from nerve injuries. Spinal cord injuries often force the medical community and make them to do something. In this context, with hoping that these cells can be improved, some interventions are performed. Discovery of the potential use of stem cells in neural repair and regeneration is a noteworthy development in the neurosciences [51]. Stem cells are also great bucks and news related to their development is always a step ahead of neural development. The reality, however, should mitigate this enthusiasm. There are limited evidences of animal models in which stem cells improve functional results that are exposed to injury in their spinal cord, but methods in which improvement of function is achieved are still unknown. Obtained evidences from uncontrolled human trials are not convincing. These factors can cause neural network changes after SCT and the neural changes can make neuro-cognitive impairments. Neural changes with SCT are important such as cells differentiation, control switches or messenger changes, nerve cells stimulation, neurons migration, motor neurons changes, sensory and autonomic system changes, regeneration of axons, myelination and conventional methods.

\section{Importance of neuro-cognitive assessment and reha-} bilitation (NCAR) after SCT in SCI

NCAR programs are used to improve brain functions. Cognitive rehabilitation therapy (CRT) will show that the cognitive treatments led to enhanced cognitive and mental performance is unambiguous $[\mathbf{1 1}, \mathbf{5 2}, \mathbf{5 3}]$. Neuro-cognitive deficits are potential side effects of hematopoietic SCT (HSCT). A substantial number of patients revealed evidence of cognitive deficits a long time after HSCT [33]. Many researches in functional neurosurgery are associated with cognitive mapping system. In fact, internal and external interferences will affect their environment and make the patient's brain functions easier. These treatments are designed for different aspects of rehabilitation treatment and can increase the focus on cognitive skills including motor control [12].The goal is cognitive functioning promotion. Today, through innovative treatment programs, the best approach is performed by expert therapists. They are doing it in the following ways: Re-use strategies, skills compensatory education, cognitive consultation, environmental restoration, combining education with job training opportunities and following-up the patients. Neuro-Cognitive Assessment and Rehabilitation (NCAR) is a vital part of the patient's treatment plan in neurosurgery such as SCl with SCT [54-56]. Neurocognitive rehabilitation therapies promote cognitive system skills with movement disorder. Cognitive, behavioral and social changes improve with a modern approach to the CRT. This method was designed primarily based on outpatient procedures. Ideally, modern NCAR is a combination of rehabilitation programs that are being undertaken by the computer on an outpatient basis $[57,58]$.

Generally when a combination of internal and external interventions occurs, the modern view becomes the most effective method. In fact, this treatment was developed first to help the patients before and after SCT but today it is for the treatment of cognitive disorders caused by brain injury, head trauma, spinal injuries, and brain tumors. NCR is based on neuroplasticity and it is brain ability for detecting and generating paths and circuits in response to our environment and more importantly in response to our thoughts. The brain has the ability to be changed during life and it is like a plastic. Recent researches have shown that stem cells in the brain can cause the growth of new neurons in any age [59-61]. Neuroplasticity principles include attention, focus, intensity, duration, constraint, immersion, imitation and visualization. Focus was causes some changes occur in the structure and organization of the brain [32]. Brain chooses when to focus on our senses. Stimulating by focus on our senses enables 
Zarghi et al. Neuroscience Discovery 2014,

the brain to be stimulated in certain areas. Neurons that are stimulated together are related with each other and these neurons create circuits and pathways in the brain and strengthen them. When two events occur simultaneously, they are related to each other in the brain and mind. Intensity/ intense experience require very careful organization in the brain. Stimulation intensity will determine the way of evolution and growth of neurons. Nurturing stimulation and education levels are the most effective agents for positive effects. Duration of neuroplasticity events can play a role in rehabilitation which is short-term or long-term. Rapid expansion of brain maps and drawing occurs that cause remembering people names in a meeting and learning fast for a test are of this kind. The long-term type which is for permanent effects may require several months. Brain maps are small in terms of size but the involved neurons are very efficient. When a patient is forced to use strong circuits, restrictions and enforcement/reorganization of the brain can be facilitated. This patient should be able to classify the data again by use of weaker circuits [62]. Surgery can cause brain damage and often patients can come back to their critical abilities. Exposure to the equal opportunity has limitation and compulsion. Exposure in position can provide the necessary obligation for neuroplasticity. In imitation, mirror neurons cause the activation of same parts of viewers' brain and this is done when they are looking at another one doing his work. Frontal lobe of the human brain prevents from actual engaging in activities. This category provides more possibility of learning for patients. Embodiment is an activity that activates similar areas of the brain involved in doing actual activities. Skills can be upgraded and can only be strengthened through visualization [62]. Neuroplasticity and reorganization of cortical damage by morphological and physiological reactions in nerve reconstruction techniques are the basis of neuro-cognitive rehabilitation which is affected by the environment, stimulation complexity, repeated tasks and motivation. Today, $\mathrm{SCl}$ management is important and includes maintaining of static damaged parts by external devices to minimize the risk of further injury, optimizing the blood pressure and to maintain cord perfusion. Falling of the blood pressure is a result of vasomotor tone deficiency. This may necessitate the use of vasopressors in order to reduce surgery pressure in the compressed cord which is followed by stability. Neurological status of each patient may reflect neuropathology of the lesion. Whether there is neural functions or not or only parts of them are preserved, is determined by the segmental level and also by any of the remaining nerve tracts in the white matter which have been safe from injury $[\mathbf{3 4}, \mathbf{5 4}, \mathbf{6 3}, \mathbf{6 4}]$. However, there is one condition that there must be a number of remaining axonal tracts. Although they are placed continuously across the lesion, it is less than the amount that is able to continue maintenance of their voluntary motor activity in the lower or upper parts. These activities must be done to have "sense". Signals that are transmitted across the lesion will cause incomplete mode in the injuries and make a good connection with anatomic findings related to the disease which is associated with preservation of white matter bridging in the lesion. These incomplete patients provide very good field for neurologists who are doing the regenerating operation. These specialists are always trying to benefit the remaining functions and increase them $[9,65]$. These factors are important for assessment of before SCT and rehabilitation results. Neurological and cognitive status of each patient with $\mathrm{SCl}$ will not be clear approximately within 3 weeks or more after the injury and even after about a year. Their situation can be improved to some extent. In addition to obvious neurological defects, the clinical picture in each of the cases will be so complicated with unwanted abnormal neural activity. It seems that this type of unwanted side effects of $\mathrm{SCl}$ are caused by increased stimulation of stimulants or through inhibiting the neuronal threshold along with the effects related to flexibility of CNS tissue. New connections are caused neural changes and these are important for rehabilitation methods. Known neurophysiological changes and micro anatomical changes occur in neuronal networks and bellow the lesion, following $\mathrm{SCl}$ that is dynamic, complex, and continuously evolving. However, neuropathological sequences are similar to reactive cellular changes in the level of lesion, distal Wallerian degeneration, and altered neuropathological functions above and below $[4,10,56]$. Improved neurological functions using pharmacological interventions are likely to be accompanied by neurological rehabilitation interventions to achieve desired goals. NCR is a multidisciplinary science using by different specialists.

\section{Conclusions}

NCAR can be helpful in patients with movement disorder that have cognitive challenges such as self-sufficiency, self-care, keeping appointments and knowing others. In some cases, the CRT gives the poor learning ability of practical skills. Beside its use in cognitive rehabilitation disorders, it is a novel method for research efforts to provide guidance in this area. Today, the effects of cognitive rehabilitation therapy using fMRI, SPECT, PET techniques have both studied and evaluated. Metacognitive strategies to be used include helping raise awareness of patients and considering solving skills along with learning how to monitor the effectiveness of these skills and when necessary to self-medicate. Computerized cognitive rehabilitation in recent years is one of the most effective treatments for cognitive rehabilitation therapy after neurosurgery. NCR is an advanced practical and theoretical method that has been made in neuroscience.

Artificial limbs and "smart" nano-technology-dependent cell transplantation and neurological functions provide the ability to re-establish the proper experience and optimal learning environments through the science of rehabilitation. Within the literature, it is suggested that further researches into the fractionation of NCAR should be explored so that neurocognitive therapists become successful to treat these 
Zarghi et al. Neuroscience Discovery 2014,

patients through the new methods.

List of abbreviations

$\mathrm{SCl}$ : Spinal cord injury

NCR: Neuro-cognitive rehabilitation

SCT: Stem cell therapy

CNS: Central nervous system

NCAR: Neuro-Cognitive Assessment and Rehabilitation

HSCT: Hematopoietic SCT

CRT: Cognitive rehabilitation therapy

fMRI: Functional magnetic resonance imaging

SPECT: Single-photon emission computed tomography

PET: Positron emission tomography

FNRC: Functional Neurosurgery Research Center

\section{Competing interests}

The authors declare that they have no competing interest.

Authors' contributions

\begin{tabular}{|l|c|c|c|c|}
\hline Authors' contributions & AZ1 & AZ2 & FA & SM \\
\hline Research concept and design & $\checkmark$ & $\checkmark$ & $\checkmark$ & $\checkmark$ \\
\hline Collection and/or assembly of data & $\checkmark$ & $\checkmark$ & $\checkmark$ & $\checkmark$ \\
\hline Data analysis and interpretation & $\checkmark$ & -- & -- & -- \\
\hline Writing the article & $\checkmark$ & $\checkmark$ & -- & -- \\
\hline Critical revision of the article & $\checkmark$ & $\checkmark$ & $\checkmark$ & -- \\
\hline Final approval of article & $\checkmark$ & $\checkmark$ & -- & -- \\
\hline Statistical analysis & $\checkmark$ & -- & -- & -- \\
\hline
\end{tabular}

Acknowledgement

This study was supported by Functional Neurosurgery Research

Center (FNRC) of Shahid Beheshti University of Medical

Sciences. We are thankful to FNRC for his logistic support.

Publication history

EIC: Tadanori Tomita, Northwestern University Feinberg School of Medicine, USA.

Received: 12-Sep-2013 Revised: 01-Jan-2014

Accepted: 05-Jan-2014 Published: 10-Jan-2014

\section{References}

1. Hughes JT. Pathology of the spinal cord. Major Problems Pathol. 1987; 6:251-257.

2. Kakulas BA. Problems and solutions in the rehabilitation of patients with progressive muscular dystrophy. Scand I Rehabil Med Suppl. 1999; 39:23-37. | PubMed

3. Kakulas BA. A review of the neuropathology of human spinal cord injury with emphasis on special features. J Spinal Cord Med. 1999; 22:119-24. | Article | PubMed

4. Kakulas BA. The applied neuropathology of human spinal cord injury. Spinal Cord. 1999; 37:79-88. | Article | PubMed

5. Kakulas BA, Taylor JT: Pathology of injuries of the vertebral column and spinal cord. In: P.J. Vinken, B.W. Bruyn, H.L. Klauwens, H.L. Frankel (eds), Handbook of Clinical Neurology. Elsevier Sciences Publishers: Amsterdam 1992; 21-51.

6. Willen JA, Gaekwad UH and Kakulas BA. Burst fractures in the thoracic and lumbar spine. A clinico-neuropathologic analysis. Spine. 1989; 14:1316-23. | Article | PubMed

7. Dimitrijevic MR. Residual motor functions in spinal cord injury. In: Waxman SG. Functional Recovery in Neurological Disease. Raven Press New York. 1988; 139-155. I Pdf

8. Kakulas $B A$, Lorimer RL and Gubbay $A D$. White matter changes in human spinal cord injury. In: E. Stalberg, H.R. Sharma, Y. Olsson (eds), Spinal Cord Monitoring. Basic Principles, Regeneration, Pathophysiology and Clinical Aspects. Springer-Verlag Publishers: Wein, New York 1998; 395-407. | Book

9. Amonn F, Frolich J, Breuer D, Banaschewski T and Doepfner M. Evaluation of a computer-based neuropsychological training in children with attention-deficit hyperactivity disorder (ADHD). NeuroRehabilitation. 2013; 32:555-62. | Article | PubMed

10. Bray GM, Villegas-Perez MP, Vidal-Sanz M, Carter DA and Aguayo AJ. Neuronal and nonneuronal influences on retinal ganglion cell survival, axonal regrowth, and connectivity after axotomy. Ann N Y Acad Sci. 1991; 633:214-28. | Article | PubMed

11. Raisman G. A promising therapeutic approach to spinal cord repair. $J R$ Soc Med. 2003; 96:259-61. | Article | PubMed Abstract | PubMed Full Text

12. Wamil AW, Wamil BD and Hellerqvist CG. CM101-mediated recovery of walking ability in adult mice paralyzed by spinal cord injury. Proc Natl Acad Sci U S A. 1998; 95:13188-93. | Article | PubMed Abstract | PubMed Full Text

13. Bracken MB, Shepard MJ, Collins WF, Holford TR, Young W, Baskin DS, Eisenberg HM, Flamm E, Leo-Summers L, Maroon J and et al. A randomized, controlled trial of methylprednisolone or naloxone in the treatment of acute spinal-cord injury. Results of the Second National Acute Spinal Cord Injury Study. N Eng/ J Med. 1990; 322:1405-11. | Article | PubMed

14. Bunge RP, Puckett WR, Becerra JL, Marcillo A and Quencer RM. Observations on the pathology of human spinal cord injury. A review and classification of $\mathbf{2 2}$ new cases with details from a case of chronic cord compression with extensive focal demyelination. Adv Neurol. 1993; 59:75-89. | PubMed

15. Guttman L. Spinal cord injuries: comprehensive management and research. Oxford: Blackwell Scientific Publications 1973.

16. Ito T, Oyanagi K, Wakabayashi K and Ikuta F. Traumatic spinal cord injury: a neuropathological study on the longitudinal spreading of the lesions. Acta Neuropathol. 1997; 93:13-8. | Article | PubMed

17. Kakulas BA and Bedbrook GM. Pathology of injuries of the verteral column with emphasis on the macroscopical aspects. In: P.J. Vinken, G.W. Bruyn (eds) in collaboration with R. Braakman, H.L. Klawans Jr (Assoc Ed), Handbook of Clinical Neurology. Injures of the Spine and Spinal Cord Part I 1976; 25:27-42.

18. Tator $\mathrm{CH}$. Biology of neurological recovery and functional restoration after spinal cord injury. Neurosurgery. 1998; 42:696-707; discussion 7078. | Article | PubMed

19. Tator $\mathrm{CH}$. Update on the pathophysiology and pathology of acute spinal cord injury. Brain Pathol. 1995; 5:407-13. | Article | PubMed

20. Bach-y-Rita P. Theoretical aspects of sensory substitution and of neurotransmission-related reorganization in spinal cord injury. Spinal Cord. 1999; 37:465-74. | Article | PubMed

21. Brook GA, Plate D, Franzen R, Martin D, Moonen G, Schoenen J, Schmitt $A B$, Noth J and Nacimiento W. Spontaneous longitudinally orientated axonal regeneration is associated with the Schwann cell framework within the lesion site following spinal cord compression injury of the rat. J Neurosci Res. 1998; 53:51-65. | Article | PubMed

22. Buss A, Brook GA, Kakulas B, Martin D, Franzen R, Schoenen J, Noth J and Schmitt AB. Gradual loss of myelin and formation of an astrocytic scar during Wallerian degeneration in the human spinal cord. Brain. 2004; 127:34-44. | Article | PubMed

23. Hess DC, Hill WD, Carroll JE and Borlongan CV. Do bone marrow cells generate neurons?. Arch Neurol. 2004; 61:483-485. | Article

24. Nacimiento W, Brook GA and Noth J. Lesion-induced neuronal reorganization in the spinal cord: morphological aspects. Adv Neurol. 1997; 73:37-59. | PubMed

25. Ramon CA, Plant GW, Avila J and Bunge MB. Long-distance axonal regeneration in the transected adult rat spinal cord is promoted by olfactory ensheathing glia transplants. J Neurosci. 1998; 18:38033815. | Pdf

26. Rapalino O, Lazarov-Spiegler O, Agranov E, Velan GJ, Yoles E, Fraidakis M, Solomon A, Gepstein R, Katz A, Belkin M, Hadani M and Schwartz M. Implantation of stimulated homologous macrophages results in partial 
recovery of paraplegic rats. Nat Med. 1998; 4:814-21. | Article | PubMed

27. Schmitt AB, Breuer S, Polat L, Pech K, Kakulas B, Love S, Martin D, Schoenen J, Noth J and Brook GA. Retrograde reactions of Clarke's nucleus neurons after human spinal cord injury. Ann Neurol. 2003; 54:534-9. | Article | PubMed

28. Barker RA, Jain M, Armstrong RJ and Caldwell MA. Stem cells and neurological disease. J Neurol Neurosurg Psychiatry. 2003; 74:553-7. I Article | PubMed Abstract | PubMed Full Text

29. Bregman BS, McAtee M, Dai HN and Kuhn PL. Neurotrophic factors increase axonal growth after spinal cord injury and transplantation in the adult rat. Exp Neurol. 1997; 148:475-94. | Article | PubMed

30. Lemoine NR. The power to deliver: stem cells in gene therapy. Gene Ther. 2002; 9:603-5. | Article | PubMed

31. Liu S, Qu Y, Stewart TJ, Howard MJ, Chakrabortty S, Holekamp TF and McDonald JW. Embryonic stem cells differentiate into oligodendrocytes and myelinate in culture and after spinal cord transplantation. Proc Natl Acad Sci U S A. 2000; 97:6126-31. | Article | PubMed Abstract | PubMed Full Text

32. Medina J. Brain Rules: 12 Principles for Surviving and Thriving at Work. Home and School, Seattle, WA: Pear Press, 2008.

33. Poppelreuter M, Weis J, Mumm A, Orth HB and Bartsch HH. Rehabilitation of therapy-related cognitive deficits in patients after hematopoietic stem cell transplantation. Bone Marrow Transplant. 2008; 41:79-90. | Article | PubMed

34. Ross L, Harvey $L$ and Lannin NA. A randomised controlled trial of upper limb motor training after acquired brain impairment. Brain Impairment. 2008; 9:91.

35. Tai YT and Svendsen CN. Stem cells as a potential treatment of neurological disorders. Curr Opin Pharmacol. 2004; 4:98-104. | Article | PubMed

36. Yandava BD, Billinghurst LL and Snyder EY. "Global” cell replacement is feasible via neural stem cell transplantation: evidence from the dysmyelinated shiverer mouse brain. Proc Natl Acad Sci U S A. 1999; 96:7029-34. | Article | PubMed Abstract | PubMed Full Text

37. Wagers AJ, Christensen JL and Weissman IL. Cell fate determination from stem cells. Gene Ther. 2002; 9:606-12. | Article | PubMed

38. Morin-Richaud C, Feldblum S and Privat A. Astrocytes and oligodendrocytes reactions after a total section of the rat spinal cord. Brain Res. 1998; 783:85-101. | Article | PubMed

39. Musumeci G, Sciarretta C, Rodriguez-Moreno A, Al Banchaabouchi M, Negrete-Diaz V, Costanzi M, Berno V, Egorov AV, von Bohlen Und Halbach $\mathrm{O}$, Cestari V, Delgado-Garcia JM and Minichiello L. TrkB modulates fear learning and amygdalar synaptic plasticity by specific docking sites. $J$ Neurosci. 2009; 29:10131-43. | Article | PubMed

40. Pearse DD, Pereira FC, Marcillo AE, Bates ML, Berrocal YA, Filbin MT and Bunge MB. CAMP and Schwann cells promote axonal growth and functional recovery after spinal cord injury. Nat Med. 2004; 10:610-6. | Article | PubMed

41. Plant GW, Christensen CL, Oudega M and Bunge MB. Delayed transplantation of olfactory ensheathing glia promotes sparing/ regeneration of supraspinal axons in the contused adult rat spinal cord. J Neurotrauma. 2003; 20:1-16. | Article | PubMed

42. Saporta S, Kim JJ, Willing AE, Fu ES, Davis CD and Sanberg PR. Human umbilical cord blood stem cells infusion in spinal cord injury: engraftment and beneficial influence on behavior. J Hematother Stem Cell Res. 2003; 12:271-8. | Article | PubMed

43. Harvey LA, Glinsky JA, Katalinic OM and Ben M. Contracture management for people with spinal cord injuries. NeuroRehabilitation. 2011; 28:17-20. | Article | PubMed

44. Alvarez-Buylla A, Garcia-Verdugo JM and Tramontin AD. A unified hypothesis on the lineage of neural stem cells. Nat Rev Neurosci. 2001; 2:287-93. | Article | PubMed

45. Falci SP, Indeck $C$ and Lammertse DP. Posttraumatic spinal cord tethering and syringomyelia: surgical treatment and long-term outcome. $J$ Neurosurg Spine. 2009; 11:445-60. | Article | PubMed

46. Hayflick L. Mortality and immortality at the cellular level. A review. Biochemistry (Mosc). 1997; 62:1180-90. I PubMed

47. Ji SJ and Jaffrey SR. Intra-axonal translation of SMAD1/5/8 mediates retrograde regulation of trigeminal ganglia subtype specification.
Neuron. 2012; 74:95-107. | Article | PubMed Abstract | PubMed Full Text 48. Moreno-Flores MT, Diaz-Nido J, Wandosell F and Avila J. Olfactory Ensheathing Glia: Drivers of Axonal Regeneration in the Central Nervous System? J Biomed Biotechnol. 2002; 2:37-43. | Article | PubMed Abstract | PubMed Full Text

49. Tessler A, Fischer I, Giszter S, Himes BT, Miya D, Mori F and Murray M. Embryonic spinal cord transplants enhance locomotor performance in spinalized newborn rats. Adv Neurol. 1997; 72:291-303. | PubMed

50. Wu S, Suzuki Y, Kitada M, Kitaura M, Kataoka K, Takahashi J, Ide C and Nishimura Y. Migration, integration, and differentiation of hippocampusderived neurosphere cells after transplantation into injured rat spinal cord. Neurosci Lett. 2001; 312:173-6. | Article | PubMed

51. Agrawal $S$ and Schaffer DV. In situ stem cell therapy: novel targets, familiar challenges. Trends Biotechnol. 2005; 23:78-83. | Article | PubMed

52. Herrmann D, Yoder C, Gruneberg M and Payne DC. Applied cognitive psychology. Mahwah, NT: Erlbaum 2006. | Website

53. Rosenfeld JV and Gillett GR. Ethics, stem cells and spinal cord repair. Med J Aust. 2004; 180:637-9. | Article | PubMed

54. Zarghi A, Zali A, Tehranidost M, Zarindast MR, Ashrafi F, Doroodgar S and Khodadadi SM. The Relationship between Age, Sex and Education Variables with Selective, Sustained Attention and Planning through Cognitive Tasks among Healthy Adults. Basic and Clinical Neuroscience. 2011; 2:58-67. | Website

55. Zarghi A, Zali A, Tehranidost M, Ashrafi F, Zarindast MR, Moazezi M and Khodadadi SM. Assessment of Selective Attention with CSCWT (Computerized Stroop Color-Word Test) Among Children and Adults. US-China Education Review A. 2012; 1:121-127. | Pdf

56. Zarghi A, Zali A, Tehranidost M, Zarindast MR, Ashrafi F and Khodadadi $M$. Comparative assessment of neuro-cognitive impairments among patients with brain tumor and healthy adults. Turk Neurosurg. 2012; 22:309-16. | Article | PubMed

57. Schindler I, Kerkhoff G, Karnath HO, Keller I and Goldenberg G. Neck muscle vibration induces lasting recovery in spatial neglect. J Neurol Neurosurg Psychiatry. 2002; 73:412-9. | Article | PubMed Abstract | PubMed Full Text

58. Stuss DT, Robertson IH, Craik FI, Levine B, Alexander MP, Black S, Dawson D, Binns MA, Palmer H, Downey-Lamb M and Winocur G. Cognitive rehabilitation in the elderly: a randomized trial to evaluate a new protocol. J Int Neuropsychol Soc. 2007; 13:120-31. | Article | PubMed

59. Faddy K, McCluskey A and Lannin NA. Interrater reliability of a new handwriting assessment battery for adults. Am J Occup Ther. 2008; 62:595-9. | Article | PubMed

60. Lannin NA and Ada L. Neurorehabilitation splinting: theory and principles of clinical use. NeuroRehabilitation. 2011; 28:21-8. | Article | PubMed

61. Schwartz JM. The Mind and the Brain: Neuroplasticity and the Power of Mental Force. New York, NY: Harper Perennial. 2003. | Book

62. Begley S. Train you're Mind, Change Your Brain: How a New Science Reveals Our Extraordinary Potential to Transform Ourselves. New York, NY: Ballantine Books. 2007. | Book

63. Foy CM and Somers JS. Increase in functional abilities following a residential educational and neurorehabilitation programme in young adults with acquired brain injury. NeuroRehabilitation. 2013; 32:671-8. | Article I PubMed

64. Lannin NA and Laver KE. The journey from research to practice: a road less travelled. Aust Occup Ther J. 2012; 59:401. | Article | PubMed

65. Herman R, He J, D'Luzansky S, Willis W and Dilli S. Spinal cord stimulation facilitates functional walking in a chronic, incomplete spinal cord injured. Spinal Cord. 2002; 40:65-8. | Article | PubMed

\section{Citation:}

Zarghi A, Zali A, Ashrafi F and Moazezi S. Neurocognitive rehabilitation among patients with spinal cord injury treated with stem cell. Neurosci Discov. 2014; 2:2. http://dx.doi.org/10.7243/2052-6946-2-2 